\title{
Effects of race and cigarette flavour on perception of cigarette smokers
}

Suzanne C Segerstrom, William J McCarthy, Todd M Gross, Nicholas H Caskey, Martin R Rosenblatt, Catherine L Carpenter, Murray E Jarvik

\begin{abstract}
Objective - To observe any effects of the targeted advertising of menthol cigarettes to black communities on subjects' imagery of smokers.
\end{abstract}

Design-2 $2 \times 2 \times 2$ complete factorial including effects of subject race (black/ white), subject smoking status (ever smoked/never smoked), target race (black/white), and target cigarette flavour (menthol/regular).

Setting-Community college and university.

Subjects-Convenience sample of 100 black and 94 white students.

Main outcome measures - Ratings of a written description of a target smoker on 15 seven-point bipolar semantic differential scales describing possible aspects of a smoker's image.

Hypothesis-Consistent with targeted advertising images, black menthol target smokers and white regular target smokers would be viewed most positively. Results-Black target smokers were rated significantly more athletic, strong, winner, and works hard than white target smokers. Target race interacted with target cigarette on the athletic and winner scales. However, only one interaction was in the predicted direction.

Conclusions - There is not a systematic image of a menthol smoker; menthol smoking may be determined by multiple factors rather than being driven primarily by advertising imagery. Black smokers, however, were seen consistently more positively than white smokers by both black and white subjects. This suggests that targeted advertising to black communities has been successful in creating a positive image of a black smoker. Public health efforts to counteract this effect need to be devised.

(Tobacco Control 1994; 3: 30-36)

\section{Introduction}

In 1988, age-adjusted mortality rates per 100000 people attributable to smoking were 437.3 for black adults and 389.3 for white adults in the US ${ }^{1}$ despite the fact that black smokers usually show lower per-smoker tobacco consumption. ${ }^{2-5}$ Black smokers suffer disproportionately from smoking-related dis- eases such as lung cancer, ${ }^{1}$ cardiovascular disease ${ }^{7}$ and cerebrovascular disease. ${ }^{6,7}$

Roughly three-quarters of black smokers in the US smoke mentholated cigarettes, while only one-quarter of white smokers do so. ${ }^{8}$ This difference has been suggested as one of the possible reasons for black-white discrepancies in smoking-related morbidity and mortality. ${ }^{9}$ Recent research into the potential health hazards of mentholated cigarettes has indicated that, compared with regular cigarettes, smoking mentholated cigarettes may result in increased carbon monoxide absorption, perhaps through a physiological effect of menthol on lung tissue. ${ }^{10}$ Menthol may also promote deeper and/or more prolonged inhalation through its cooling effect. Finally, menthol cigarettes have been reported to have a higher tar and nicotine content than regular cigarettes, ${ }^{3,11}$ although the 1989 Surgeon General's report ( $p$ 317) found no correlation between mentholation and high tar yield. ${ }^{12}$

Image considerations may play a role in the choice of menthol or regular cigarettes. Both the choice to smoke and cigarette brand choice may be related to image considerations. ${ }^{13-16}$ The more one values the imagery associated with smoking a certain brand of cigarettes, the more likely one is to choose that brand. The black community has been preferentially targeted with advertising for menthol cigarettes $^{9,17}$ (Jarvik ME, paper presented at the annual meeting of the American Psychological Society, San Diego, California, 20-22 June 1992), possibly creating a positive image of the menthol smoker within that community that encourages black smokers to choose menthol cigarettes. This choice may, in turn, be contributing to increased smoking-related disease and mortality among black smokers.

To explore the possibility that a more desirable image of menthol cigarettes and menthol cigarette smokers exists in targeted populations, black and white subjects were asked to rate black and white smokers of both menthol and regular cigarettes on adjectives which describe aspects of a smoker's image. We predicted that, consistent with advertising images, black menthol and white regular target smokers would be seen in the most positive light. We further predicted that this interaction would be moderated by the subject's race and smoking status; that is, subjects would view a target of their own race more positively, and smokers would see the smoking target more 
positively than non-smokers. Furthermore, if the predicted interaction between race and cigarette preference were only present in smokers, an interaction between race, cigarette preference, and smoking status would be observed.

\section{Methods \\ SUBJECTS}

Subjects were 194 black and white college students recruited from introductory psychology classes at two sites: a community college and a large university. Subjects at the university received class credit for their participation. An additional 183 students who indicated their race as Asian, Hispanic, or other completed the questionnaire. However, these subjects were not included in this study because, while we could reasonably predict and understand differences in attitudes toward black and white targets from black and white subjects, we could not do so accurately for other ethnic groups. To be able to interpret target race $\times$ subject race effects accurately, we restricted the sample for this study to black and white subjects.

Smoking status was evaluated with two questions: first, whether the subject had smoked 100 or more cigarettes in his or her lifetime; second, whether the subject currently smoked. Subjects who answered "yes" to the second question were designated current smokers $(n=29)$; those who answered "yes" to the first question but "no" to the second question were designated former smokers ( $\mathrm{n}=$ 21 ); and those who answered "no" to both questions were designated never-smokers $(\mathrm{n}=$ 144).

Black subjects were significantly older than white subjects $(t=5.08, p<0.0001)$, and were significantly more likely to be students at the community college $\left(\chi^{2}=70.16, p<0.001\right)$. There was also a significantly lower proportion of men among black subjects $\left(\chi^{2}=3.99, p<\right.$ $0.05)$. Proportions of current, former, and never-smokers, as well as the number of friends and family of the subject who smoked, did not differ significantly between black and white subjects (table 1).

\section{PROCEDURE}

Questionnaires were administered during regular class sessions. Subjects were informed that their responses were confidential and that their participation would not affect their standing in the course or with the professor, and they were instructed not to put any identifying information on the questionnaire. At both sites the professor left the room during questionnaire administration and collection. Subjects were given the following instructions in either oral or written form, depending on the preference of the professor:

"This is a two-part questionnaire. In the first part, you will be given some brief information and asked to make ratings based on this information. This may seem difficult, but please make these ratings based on your first impression of the material. When you
Table 1 Demographic characteristics of black and white subjects

\begin{tabular}{lcc}
\hline & \multicolumn{2}{c}{ Subject race } \\
\cline { 2 - 3 } Demographics & Black & White \\
\hline n & 100 & 94 \\
Age (Sex (\% male) & 26.67 & 20.68 \\
School (\% community college) & 21.21 & 34.04 \\
English spoken & 87.00 & 27.66 \\
as a child (\% yes) & & \\
Smoking status & 92.93 & 88.30 \\
\% current & & \\
\% former & 14.00 & 16.30 \\
\% never & 10.24 & 10.30 \\
Friends and family who smoke & 75.76 & 73.40 \\
\% "None" & & \\
\% "Hardly any" & 20.00 & 13.83 \\
\% "About half" & 55.00 & 64.89 \\
\% "Most" & 21.00 & 18.09 \\
& 4.00 & 3.19 \\
\end{tabular}

have finished the first part, please turn the page and answer all questions on the second page which apply to you. The questions in the shaded area may not apply to you; if not, you may leave this section blank. Please do not discuss this questionnaire with people around you until after the session. Thank you very much for your participation."

Subjects were then handed a two-page questionnaire. On the first page, a written description of a target smoker was given. Written descriptions of people (targets) have consistently elicited images of those people in the social perception literature. ${ }^{18-20}$

Sixteen descriptions of target smokers were created by varying age, sex, race, and cigarette preference. Each subject was asked to rate one of these descriptions, which were handed out at random. Because, in analyses presented below, some characteristics of the subjects race, for example - will be identical to that of the target, target characteristics will be distinguished from subject characteristics by the use of italics for target characteristics. The description of the target read as follows:

"John (Cathy) Smith is a 20-(40-)year-old white (black) man (woman) who lives in Los Angeles. He (She) smokes regular (menthol) cigarettes."

This description was followed by 15 sevenpoint bipolar semantic differential scales which had adjective pairs as endpoints. These adjectives described possible aspects of a smoker's image (see table 2). The 15 scales were listed in random order. Each block of four scales was then constrained to have two scales for which the more valued of the adjective pair would lie to the right and two to the left. Order within

Table 2 Endpoints of semantic differential scales

rich...poor

masculine... feminine

unpopular... popular

nervous ... calm

acts normal ... acts crazy

sick... healthy

smart... stupid

weak... strong

tough ... sensitive

lazy ... works hard

inactive.... athletic

good-looking ... ugly

a loser ... a winner

confident.... afraid

outgoing... shy 
the block was randomised by coin toss. For scales for which "more valued" was not a salient criterion (eg, masculine/feminine), the direction of the scale was chosen at random. To determine if some adjective rating scales could be grouped together in later analyses, a principal factor analysis with varimax rotation was performed on the 15 scales. Only one factor with a value greater than one emerged; this factor accounted for $80 \%$ of the variance. Subgroups of variables were therefore not used.

Demographic information was collected on the second page of the questionnaire. Smoking-related information was contained in a shaded box at the end of the questionnaire and never-smokers were instructed not to complete this section.

\section{Results}

In planned analyses, effects of subject's smoking status (ever smoked/never smoked) and race (black/white) were evaluated along with characteristics of the smoker: cigarette type (menthol/regular) and race (black/white). We predicted that there would be an interaction between race and cigarette type. Black menthol and white regular smokers, compared to black regular and white menthol smokers, would be more likely to elicit positive evaluations. Furthermore, this interaction would be moderated by the subject's race and smoking status. Subjects would judge a target of the same race more positively, and smokers would view the targets more positively. Analyses examining subject cigarette type were not attempted due to very small subsample sizes (crossing race and cigarette type yielded cell sizes ranging from six to 14).

Analysis of predicted effects began with a multivariate analysis of covariance (MANCOVA) on the 15 adjective rating scales, controlling for subject age. MANCOVA uses multiple outcome measures to determine if groups are significantly different. It differs from multivariate analysis of variance (MANOVA) in that it holds covariates constant; that is, it partials out the variance due to the covariates (in this case, age) before comparing group means. Analysis of covariance (ANCOVA) is a similar procedure which uses only one outcome measure.

In MANCOVA analyses, significant effects were found for the main effect of target race $(F(15,160)=2.28, p<0.006)$, as well as two three-way interactions: race $\times$ race $\times$ cigarette type $(\mathrm{F}(105,1052)=1.43, \mathrm{p}<0.005)$ and smoking status $\times$ race $\times$ cigarette type $(\mathrm{F}(105,1052)=1.25, \mathrm{p}<0.05)$.

For each significant effect, univariate analyses of covariance (ANCOVAs), again holding age constant, were performed to determine if the effect was driven uniformly by all the variables or selectively by a few. Because there were no a priori hypotheses as to which variables would be significant in univariate tests, a Bonferroni correction was used for each set of tests. Dividing the overall alpha level $(0.05)$ by the number of effects tested (15) yielded a Bonferroni-corrected alpha level of 0.003 .

Four of the adjective rating scales were significant in the ANCOVAs for the main effect of race: athletic $(\mathrm{F}(1,184)=16.37, \mathrm{p}<$ $0.0001)$, strong $(\mathrm{F}(1,184)=9.98, \mathrm{p}<0.002)$, winner $(\mathrm{F}(1,184)=9.78, \mathrm{p}<0.002)$, and works hard $(F(1,184)=14.66, p<0.0002)$. In all cases, the black smoker was judged more positively than the white smoker. Table 3 contains least-squares means controlling for age for black and white smokers on the significant rating scales.

The athletic scale was also significant in both the three-way interactions: race $x$ race $\times$ cigarette type $(\mathrm{F}(7,178)=4.05, \mathrm{p}<$ $0.0004)$ and smoking status $\times$ race $\times$ cigarette type $(\mathrm{F}(7,178)=3.51, \mathrm{p}<0.002)$. In examining the pattern of the first interaction, the predicted pattern emerged: black menthol smokers were judged to be more athletic than black regular smokers, and white regular smokers were judged to be more athletic than white menthol smokers. Black smokers were, in all cases, judged to be more athletic than white smokers, and the race $\times$ cigarette type interaction was much more pronounced among white subjects than among black (table 4).

The pattern of the second interaction on the athletic scale was harder to characterise. Among subjects who were never-smokers, white regular and white menthol smokers were judged to be roughly equally athletic. Black smokers were judged to be more athletic when they smoked menthol cigarettes than when they smoked regular cigarettes. Among subjects who were smokers, both white and black smokers were judged to be slightly less athletic when they smoked menthol cigarettes. Again, black smokers were judged to be more athletic than white smokers in all cases (see table 5).

The winner scale was significant in the race $\times$ race $\times$ cigarette type interaction $(\mathrm{F}(7,178)=3.78, \mathrm{p}<0.0008)$. Among white

Table 3 Least-squares means and standard deviations (in parentheses) for significant effects of target race*

\begin{tabular}{lcc}
\hline & \multicolumn{2}{c}{ Target race } \\
\cline { 2 - 3 } Adjective & Black & White \\
\hline Athletic & $3.55(0.09)$ & $2.90(0.09)$ \\
Strong & $4.18(0.10)$ & $3.38(0.10)$ \\
Winner & $3.84(0.09)$ & $3.38(0.09)$ \\
Works hard & $3.99(0.09)$ & $3.59(0.09)$ \\
\hline
\end{tabular}

$\star$ Controlling for subject age.

$\star \star$ Higher numbers mean a stronger endorsement of this property for the target. Scale midpoint was 4 .

Table 4 Means in subject race $\times$ target race $\times$ target cigarette interaction: athletic scale

\begin{tabular}{ccc} 
& \multicolumn{2}{c}{ Subject race } \\
\cline { 2 - 3 } & Black & White \\
\hline Black target & & \\
Menthol & 3.84 & 3.99 \\
Regular & 3.79 & 3.38 \\
White target & & \\
Menthol & 3.18 & 2.54 \\
Regular & 3.29 & 2.83 \\
\hline
\end{tabular}

$\div$

$\rightarrow$

$+$

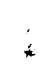

6

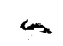

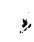

.

$-$

$-$

$-\infty$

$\rightarrow$

둔

$-$

n

:

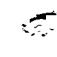

$=$

$=$

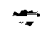

$=$

$\Rightarrow$ 
Table 5 Means in smoking status $\times$ target race $\times$ target cigarette interaction: athletic scale

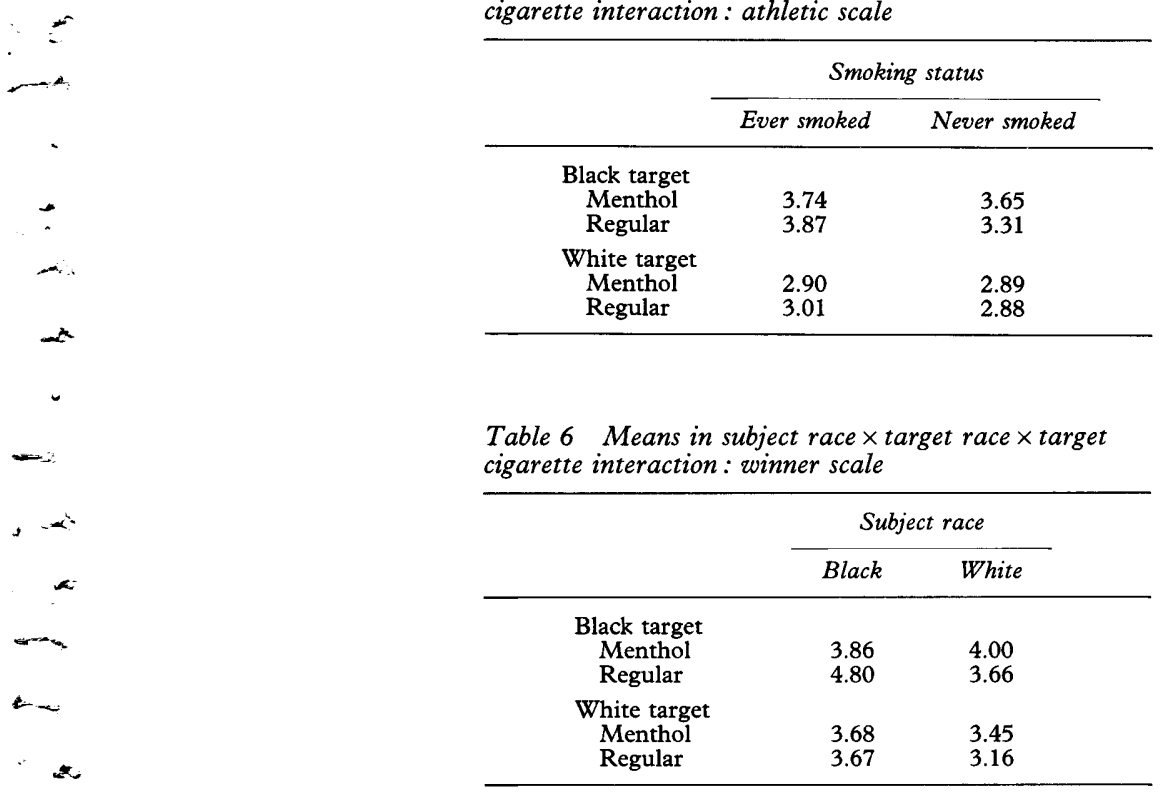

subjects, both black and white smokers were judged to be more like winners when they smoked menthol cigarettes. Among black subjects, white smokers were seen equally as winners whether they were smoking regular or menthol cigarettes, while black smokers were judged much more as winners when they were smoking regular cigarettes than menthol. Again, in all cases black smokers were judged more positively than white smokers (see table 6).

An exploratory analysis was carried out to see if the image of the target smokers was affected by the target's age or sex, characteristics not included in planned analyses. A series of MANOVAs crossing sex, race, age, and cigarette type were performed on the adjective rating scales. Type I error, accumulated by performing all the possible multivariate analyses, was controlled with a Bonferroni correction. The alpha level for these analyses was computed by dividing alpha $(0.05)$ by the number of effects (15), setting Bonferroni-corrected alpha at 0.003 . These analyses indicated that age and sex did not significantly affect perceptions of smokers (with the exception of the masculine/feminine scale). Only race yielded a significant finding $(\mathrm{F}(14,160)=3.33, \mathrm{p}<0.0001)$.

\section{Discussion}

Black communities have been targeted by cigarette advertisers in recent years (eg, by using racially matched models and advertising in black magazines) in an attempt to replace falling revenues from white smokers, who quit smoking more successfully. ${ }^{21-26}$ These data suggest that advertising has been successful in creating an image of a black smoker which is more positive than that of a white smoker: more athletic, strong, a winner, and working hard. While the mean ratings of these smokers usually fell on the negative side of a bipolar scale, many mean ratings of black targets fell at the midpoint or on the positive side. This was not true of white targets. The more positive image of a black smoker suggested by these data may be contributing to the higher rates of smoking in this community as members attempt to acquire this positive image.

Both black and white subjects held a more positive image of a black smoker than of a white smoker. One might expect to find an interaction in which subjects rated targets of their own race more highly. The lack of such an interaction suggests that among both black and white subjects, a black smoker was somehow more acceptable than a white smoker. This effect may, in part, be driven by public health campaigns, which until recently have been dominated by white models. The overall image of a black smoker may be profiting from the lack of negative public health images to offset positive advertising images.

While cigarette advertising and promotion probably increase cigarette consumption, public health campaigns have substantially decreased smoking behaviour, compared to what smoking rates would have been had no public health campaign existed. ${ }^{27-29}$ Unfortunately, negative images of smokers generated by public health campaigns seem not to be having as strong an effect on the image of a black smoker. Strong efforts need to be made to offset positive images of smoking presented to blacks and other minorities, especially given increases in targeted advertising (eg, billboards advertising cigarettes are more dense in black neighbourhoods ${ }^{17,21,30}$.

Creating a negative image of a smoker and a positive image of a non-smoker has been suggested as an effective way to combat the effects of cigarette advertising. ${ }^{31}$ This research indicates several dimensions (eg, athleticism and drive) on which public health efforts might concentrate. For example, designers of public health messages should be aware that they are battling a positive image of smoking which may specifically consist of being a winner, working hard, and being strong and athletic. Creating messages which refute the association between smoking and these characteristics may be effective. Public health efforts should also target communities in the same manner as cigarette advertisers (eg, by using ethnically matched models who engage in activities with which community members might identify). Previous public health efforts may not have been targeted effectively at black audiences.

An alternate explanation for the more positive perception of a black smoker is that the health care delivery system in general is not as accessible to blacks, who are therefore less likely to receive information about the harm associated with smoking or medical advice to quit smoking. ${ }^{32}$ However, this does not explain why white subjects found black smokers more appealing. Presumably the white subjects in this sample have not experienced the same barriers to health care that the black subjects might have.

MENTHOL

Despite the fact that mentholated cigarettes 
are preferentially advertised to black smokers $^{9,17}$ (Jarvik ME, paper presented at the annual meeting of the American Psychological Society, San Diego, California, 20-22 June 1992), the predicted interaction between cigarette flavour and race was only observed for the inactive/athletic scale, where it was much more pronounced in white subjects. Cigarette type also interacted with race and smoking status on the inactive/athletic scale. Smokers gave menthol smokers lower ratings, while neversmokers gave only black menthol smokers higher ratings. Cigarette type was also a factor in the winner/loser scale: most noticeable in this interaction was the positive rating of the black regular smoker by black subjects. This effect was in the opposite direction of that predicted, and suggests that while cigarette type may have had an effect, that effect was not systematic in terms of favouring the smoker of a menthol or regular cigarette.

If there is not a strong, systematic image of a menthol smoker, as indicated by these data, why do a majority of black smokers choose menthol cigarettes? First, menthol choice may be a function of construct(s) other than imagery, and advertising merely serves to promote or maintain the choice of one menthol cigarette brand to another. This argument is diminished to some extent by the changing rates of menthol cigarette smoking ${ }^{32,33}$ and menthol advertising, both of which have increased over the years (eg, proportion of menthol cigarette advertisements in Ebony magazine increased from $30 \%$ in 1970 to $100 \%$ in 1990; Jarvik ME, paper presented at the annual meeting of the American Psychological Society, San Diego, California, 20-22 June 1992). It is impossible in retrospect to discover if advertising created a demand for menthol cigarettes or an increasing demand led to more menthol cigarette advertising. However, it would not be unreasonable to hypothesise that increased advertising has contributed in some part to rising rates of menthol smoking. Advertising has been demonstrated to cause changes in cigarette choice in other groups (eg, children, adolescents, women) for whom a particular advertising campaign was appealing. ${ }^{12,21,34}$

Second, the nonspecific image of a smoker may have been confounded with the image of a menthol smoker in the black subjects due to their probable exposure to a preponderance of menthol advertising and smoking; the opposite may have been true of the white subjects. That is, it may have been difficult for our subjects to generate differentially the images of a menthol or regular smoker when they have been exposed to few images of the smoker type that is not prevalent in their community.

Third, advertising, and thus imagery, may not be focused on the flavour of the cigarette as much as the image of a smoker and the brand name, though one flavour or another may be emphasised. For example, Cummings et $a l^{9}$ noted that many advertisements for cigarette brands manufactured both in regular and menthol form are identical except for word order (eg, "Available in regular and menthol" as opposed to "Available in menthol and regular"). This picture of the type of targeted advertising is consistent with the findings here: a smoker's image is not systematically related to the flavour of cigarette he or she smokes. However, targeted marketing of brands that are manufactured only in menthol (eg, Kool) may lead to preferential consumption of that brand without creating a specific image of a menthol cigarette smoker.

Fourth, menthol choice may be self-perpetuating. Smokers in communities who choose menthol serve as models for other individuals in that community who begin smoking. Those individuals may be starting smoking cigarettes with which they are more familiar.

Finally, targeted advertising may be linked to targeted distribution, so that menthol cigarettes may be more readily available in communities targeted with menthol cigarette advertisements. For example, are menthol cigarettes displayed more prominently in these communities? Are more menthol brands available? In cigarette vending machines in these communities, is there a predominance of menthol brands? These are empirical questions which need to be addressed.

\section{Conclusion}

The role of advertising and imagery in the choice of menthol cigarettes by black smokers is still unclear. While it seems possible that advertising and the choice of menthol are linked, the mechanism by which this is occurring is elusive. In this sample, there were cases of black menthol smokers being perceived more positively, as well as those in which black regular smokers were perceived more positively. Menthol choice may be determined by multiple factors, with taste preference, social norms, acculturation (eg, the association of menthol with folk remedies), and image considerations converging to influence the choice of cigarette flavour.

Generalisations about the role of imagery in menthol choice should also be made cautiously from this sample to the community at large. Because this sample was composed of college students who were predominantly young and female, each of the above-mentioned factors in menthol choice may play a slightly different role than in a more representative sample. (It should be noted that the proportion of each racial group in this sample who smoked menthol was comparable to national proportions.) Furthermore, subject race, age, and data collection site shared variance in this sample. Because age was held constant in analyses, large amounts of variance due to subject race and data collection site were also held constant. This was advantageous in that it controlled for potential confounding subject differences such as socioeconomic status, but disadvantageous in that it also controlled for potentially important blocking variables such as subject race.

A second issue which affects the generalisability of this sample is the representativeness of smoking prevalence. Given national survey 
data, one might have expected a higher smoking prevalence in the black subjects (black and white subjects did not differ in smoking prevalence). Again, the difference in age between the black and white groups affects this parameter considerably. While, in general, smoking prevalence is higher in blacks than in whites, black adolescents and young adults are less likely to be smokers than white adolescents and young adults. Some data suggest that the trend reverses around ages 25 to $30^{23}$; after this age, black adults are more likely to be smokers than white adults. This crossover is most likely due to more successful quitting by white smokers as well as later age of initiation in black smokers. Therefore, the white sample was more likely to contain smokers because it was a relatively young sample. As an aside, it might be noted that this difference in age of smoking initiation also has implications for public health and intervention. Most research into the predictors of smoking initiation has been done with children and adolescents, and intervention based on this research may be more effective for white populations, who have an earlier age of initiation. Predictors of initiation at a later age, a more common pattern in black smokers, ${ }^{28}$ may be quite different.

This is clearly preliminary research and there are many other methodologies and subject pools which could be brought to bear on the issue of menthol cigarette choice. Future research should address the possibility that a different target presentation (eg, visual rather than written) could elicit results more directly related to target advertising. Second, adjective rating scales other than those chosen may yield interesting results. Third, and perhaps most important, the limitations of a convenience sample such as that described above can be addressed in future studies using communitybased samples.

With these caveats in mind, however, it is still clear that black smokers were perceived more positively than white smokers by both black subjects and white subjects. Targeted advertising in minority communities seems to be winning over existing public health efforts, as compared to the effects in non-minority communities. Minority communities should be a focus for future public health messages discouraging smoking, especially messages which present an alternative, less flattering, view of smoking. Interventions should also seek to decrease the amount of pro-smoking messages in minority communities.

This research was presented at the American Psychological Society Annual Convention, June 1993, in Chicago, Illinois, USA.

Preparation of this article was supported by the Cigarette and Tobacco Surtax Fund of the State of California through the Tobacco-Related Disease Research Program of the University of California, Grant 1RT-87. The authors are indebted to Dr of California, Grant 1RT-87. The authors are indebted to Dr Hector Myers and three anonymous reviewers for their helpful
comments on earlier versions of this manuscript, as well as Richard Haney and Dr Kathryn Welds for their assistance in data collection.

1 US Centers for Disease Control. Smoking-attributable mortality and years of potential life lost - United States, 1988. $M M W R$ 1991; 40: 62-71.

2 Kabat GC, Morabia A, Wynder EL. Comparison of smoking habits and blacks and whites in a case-control study. Am f Public Health 1991; 81 : 1483-6.

3 Royces JM, Hymowitz N, Corbett K, Hartwell TD, Orlandi MA. Smoking cessation factors among African Americans and whites. Am $\mathcal{\text { P Public Health } 1 9 9 3 ; 8 3 : 2 2 0 - 6 .}$

4 Satariano WA, Swanson GM. Racial differences in cancer incidence: The significance of age-specific patterns. Cancer 1988; 62: 2640-53.

5 Wagenecht LE, Cutter GR, Haley NJ, Sidney S, Manolio TA, Hughes GH et al. Racial differences in serum cotinine levels among smokers in the Coronary Artery Risk Development in (Young) Adults Study. Am f Public Health 1990; 80: 1053-6.

6 Sprafka JM, Folsom AR, Burke GL, Edlavitch SA. Prevalence of cardiovascular disease risk factors in blacks and whites: the Minnesota Heart Survey. Am f Public Health $1988 ; 78$ : $1546-9$.

7 Broderick JP, Brott T, Tomsick T, Huster G, Miller R. The risk of subarachnoid and intracerebral hemorrhages 326: 733-6.

8 US Department of Health and Human Services. Tobacco use in $1986:$ methods and basic tabulations from Adult Use of Tobacco Survey. Rockville, MD: US Department of
Health and Human Services, Public Health Service, Centers for Disease Control, Center for Chronic Disease Prevention and Health Promotion, Office of Smoking and Health, 1990. (DHHS Publication No. 90-2004.)

9 Cummings KM, Giovino G, Mendicino AJ. Cigarette advertising and black-white differences in brand preference. Public Health Rep 1987; 102: 698-701.

10 Miller GE, Jarvik ME, Caskey NH, Segerstrom SC, Rosenblatt MR, McCarthy WJ. Cigarette mentholation increases smokers' exhaled carbon monoxide levels. Exp Clin Psychopharmacol, in press.

11 Sidney S, Tekawa I, Friedman GD. Mentholated cigarette use among multiphasic examinees, 1979-1986. Am $\mathscr{f}$ use among multiphasic examin

12 US Department of Health and Human Services. Reducing the health consequences of smoking: 25 years of progress. $A$ report of the Surgeon General, 1989. Atlanta, Georgia: Centers for Disease Control, Office on Smoking and Health, 1989. (DHHS Publication No (CDC) 89-8411.)

13 Barton J, Chassin L, Presson CC, Sherman SJ. Social image factors as motivators of smoking initiation in early and middle adolescence. Child Dev 1982; 53: 1499-1511.

14 Bowen DJ, Dahl K, Mann SL, Peterson, AV. Descriptions of early triers. Addict Behav 1991; 16: 95-101.

15 Chassin L, Presson CC, Sherman SJ, Corty E, Olshavsky RW. Self-images and cigarette smoking in adolescence. Personal Social Psychol Bull 1981; 7: 670-6.

16 Grube JW, Rokeach M, Getzlaf SB. Adolescents' value images of smokers, ex-smokers, and nonsmokers. Addict Behav 1990; 15: 81-8.

17 Altman DG, Schooler C, Basil MD. Alcohol and cigarette advertising on bill boards. Health Educ Res 1991; 6: 487-90.

18 Bailey RC, Doriot PD. Perceptions of professionals who express religious beliefs. Social Behav Personal 1985; 13: 167-70.

19 Dion KL, Schuller RA. Ms and the manager: a tale of two stereotypes. Sex Roles 1990; 22 : 569-77.

20 Etaugh C, Birdoes LN. Effects of age, sex, and marital status on person perception. Percept Mot Skills 1991; 72: 491-7.

21 Davis RM. Current trends in cigarette advertising and marketing. $N$ Engl $\mathscr{f}$ Med 1987; 316: 725-32.

22 Ernster VL. Trends in smoking, cancer risk, and cigarette promotion: current priorities for reducing tobacco exposure. Cancer 1988; 62: 1702-12.

23 Geronimus AT, Neidert LJ, Bound J. Age patterns of smoking in US black and white women of childbearing age. Am f Public Health 1993; 83 : 1258-64.

24 Hatziandreu EJ, Pierce JP, Lefkopoulou M, Fiore MC, Mills SL, Novotny TE, et al. Quitting smoking in the United States in 1986. F Natl Cancer Inst 1990; 82. $1402-6$.

25 McWhorter WP, Boyd GM, Mattson ME. Predictors of quitting smoking: the NHANES I followup experience. quitting smoking: the NHANES I follow

26 Novotny TE, Warner KE, Kendrick JS, Remington PL Smoking by blacks and whites: socioeconomic and Smoking by blacks and whites: socioeconomic and
demographic differences. Am $\mathcal{F}$ Public Health $1988 ; 78$ : demograph

27 Laugesen $M$, Meads $C$. Tobacco advertising restrictions, price, income, and tobacco consumption in OECD countries, 1960-1986. Br $\mathcal{F}$ Addict 1991; 86: 1343-54.

28 Warner KE. The effects of the anti-smoking campaign on cigarette consumption. Am $\mathcal{f}$ Public Health 1977; 67: 645-50.

29 Witt SF, Pass CL. The effects of health warnings and advertising on the demand for cigarettes. Scot $\mathcal{F}$ Political Econ $1981 ; 28: 86-91$.

30 Mayberry RM, Price PA. Targeting blacks in cigarette billboard advertising: results from down South. Health Values 1993; 17:28-35.

31 Chapman S, Egger G. Forging an identity for the nonsmoker: The use of myth in health promotion. Internatl smoker: The use of myth in health Educ 1980; 3:1-16.

32 Orleans CT, Strecher VJ, Schoenback VJ, Salmon MA, Blackmon C. Smoking cessation initiatives for black Americans: recommendations for research and intervantion. Health Educ Res 1989; 4: 13-25. 
33 Robinson RG, Pertschuk M, Sutton C. Smoking and African Americans. In: Samuels SE, Smith MD, eds. Improving the health of the poor. Menlo Park, CA: Henry $\mathrm{J}$ Kaiser Family Foundation, 1992; 123-81.

34 Laugesen $M$, Meads $C$. Advertising, price, income and publicity effects on weekly cigarette sales in New Zealand publicity effects on weekly cigarette sales in

35 Pierce JP, Gilpin E, Burns DM, Whalen E, Rosbrook B, Shopland D, et al. Does tobacco advertising target young people to start smoking? Evidence from California. $\mathfrak{F} A M A$ 1991; 266: 3154-8.
36 Andreski P, Breslau N. Smoking and nicotine dependence in young adults: differences between blacks and whites. Drug Alcohol Depend 1993; 32:119-25.

37 Breslau N, Fenn N, Peterson EL. Early smoking initiation and nicotine dependence in a cohort of young adults. Depend 1993; 33: 129-37.

38 US Centers for Disease Control. Differences in the age of smoking initiation between blacks and whites - United States. MMWR 1991; 40: 754-7.

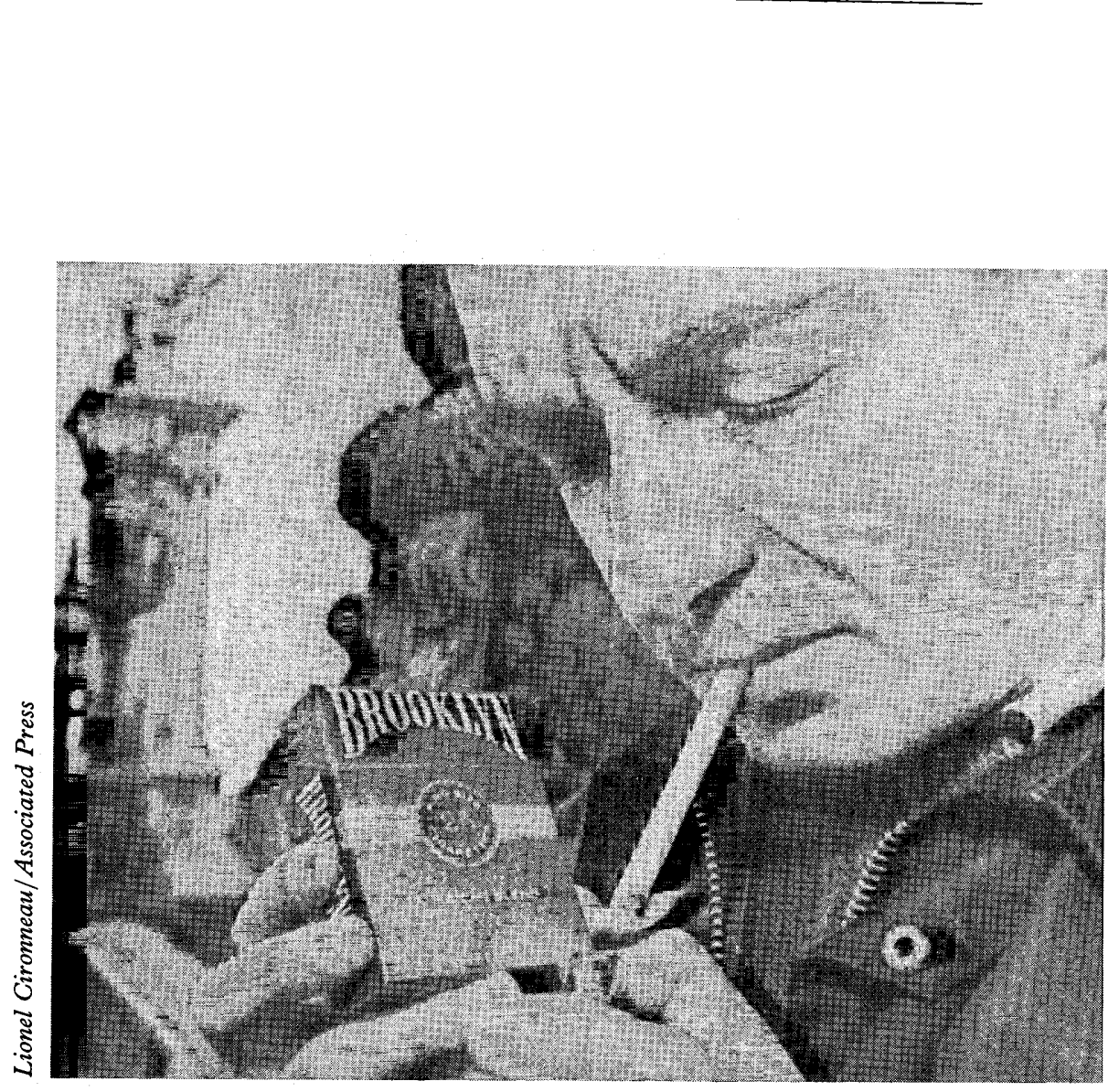

2

France's state-run tobacco company has introduced a new brand of cigarettes called "Brooklyn". According to the Detroit Free Press, they sell for US\$2.37 a pack, "or \$1,000,002.37 if you want the bridge, too". 